\title{
Reproduction of PMWS in immunostimulated SPF piglets transfected with infectious cloned genomic DNA of type 2 porcine circovirus
}

\author{
Béatrice GRASLAND ${ }^{\mathrm{a} *}$, Christophe LOIZEL ${ }^{\mathrm{a}}$, Philippe BLANCHARD ${ }^{\mathrm{a}}$, \\ Aurélie OGER ${ }^{\mathrm{a}}$, Anne-Cécile NiGNOL ${ }^{\mathrm{a}}$, Laurent BIGARRÉ ${ }^{\mathrm{a}}$, \\ Hervé MORVAN $^{\mathrm{b}}$, Roland CARIOLET ${ }^{\mathrm{a}}$, André JESTIN ${ }^{\mathrm{a}}$ \\ a French agency for food safety (AFSSA), Unit of Viral Genetics and Biosafety, \\ BP 53, 22440 Ploufragan, France \\ b LDA 22, 05-07 rue du Sabot, BP 54, 22440 Ploufragan, France
}

(Received 30 September 2004; accepted 3 February 2005)

\begin{abstract}
Postweaning multisystemic wasting syndrome (PMWS) is a recently emerged disease affecting pigs. Type 2 porcine circovirus (PCV2) has been associated with this syndrome although other factors are required in association with this virus for PMWS expression. The aim of this study was to investigate whether general immunostimulation (injections of keyhole limpet hemocyanin emulsified in incomplete Freund adjuvant and of thioglycollate medium) could strengthen the severity of PMWS in six-week-old specific-pathogen-free (SPF) piglets transfected with pure tandem-cloned PCV2 DNA by the intramuscular route. Non-immunostimulated piglets transfected with the viral clone did not present clinical signs but only mild pathological microlesions characteristic of PMWS. These piglets seroconverted and high viral genome loads and infectious titers were detected in the lymphoid organs at the end of the trial. Mild-to-moderate forms of PMWS were generally observed in the immunostimulated transfected piglets, as well as one severe form for a piglet (8003) which died. These piglets with mild-to-moderate forms had higher DNA loads than the transfected-only animals. Thus, viral replication was enhanced by immunostimulation. This is the first time that clinical PMWS has been reported in an SPF immunostimulated piglet infected with a pure inoculum consisting of tandem-cloned PCV2 DNA. This result confirms that PCV2 is the agent of PMWS and that immunostimulation could enhance PMWS in SPF piglets transfected with a PCV2 DNA clone.
\end{abstract}

porcine circovirus type 2 / immunostimulation / tandem-cloned DNA / PMWS

\section{INTRODUCTION}

A new disease of the swine, first described in Canada in 1991 [10, 17], emerged thereafter in several countries across the world $[11,29,35]$. This pathology known as the postweaning multisystemic wasting syn- drome (PMWS) [10, 17] particularly affects eight to thirteen-week-old piglets [26]. Today, it still has a major economic impact in pig producing countries [16].

The characteristic clinical signs include weight wasting, dyspnea, lymph node enlargement and less frequently pallor, pyrexia and

* Corresponding author: b.grasland@ ploufragan.afssa.fr 
diarrhea [18, 34]. The PMWS microlesions are often located in the lymphoid tissues which can present several levels of lymphocyte depletion with a loss of follicles, as well as histiocytic infiltration [33]. However, these clinical signs and histopathological lesions must be associated with the presence of type-2 porcine circovirus (PCV2) in affected tissues for the diagnosis of PMWS [38]. Indeed, PCV2 was rapidly associated with PMWS [2, 12, 28] even though initial experimental infections failed to reproduce the full spectrum of clinical signs irrespective of the type of PCV2 suspension inoculated (homogenates of PCV2 infected tissues [5] or virus propagated in cell cultures $[13,27])$. These studies demonstrated that unidentified co-factors were necessary to trigger the syndrome in PCV2infected piglets. However, some recent studies have reported reproduction of the complete disease in specific-pathogen-free (SPF) piglets [1], and in cesarean-derived colostrum-deprived piglets $[8,19]$ but with a non-purified preparation of PCV2. Moreover, the lesions were more acute when the PCV2 inoculates were combined with either porcine parvovirus (PPV) [3, 21, 22] or porcine reproductive and respiratory syndrome virus (PRRSV) [19]. The immunostimulation also influences the PMWS development [4, 23, 24, 30].

The effects of co-factors, in a model of pathogenesis, could be minimized by using a pure inoculum of PCV2. With this aim, Fenaux et al. $[14,15]$ investigated the infection ability of a PCV2 molecular DNA clone when injected directly into the liver and inguinal lymph nodes. Only mild pathological lesions were observed in four-weekold SPF piglets despite widespread distribution of the virus in their organs. As a result, the authors confirmed that although PCV2 was the agent associated with PMWS, cofactors are crucial for the development of severe clinical PMWS. The infectiousness of another PCV2 DNA clone was checked by intramuscular and intraperitoneal injections [32] with similar results [14]. Since no clinical PMWS was reproduced with this pure PCV2 inoculum, the purpose of our work was to evaluate the impact of immunostimulation on the PMWS severity level showed by six-week-old specific-pathogen-free piglets after injection of pure tandem-cloned PCV2 DNA by the intramuscular route.

\section{MATERIALS AND METHODS}

\subsection{Animals and experimental design}

\subsubsection{Animals}

The specific-pathogen-free (SPF) piglets were free from virus of the African and classical swine fever, virus of bovine viral diarrhea, Border disease virus, Aujesky disease virus, parvovirus, porcine reproductive and respiratory syndrome virus, swine influenza virus, porcine circovirus type 1 and 2, virus of transmissible gastroenteritis, porcine respiratory coronavirus, Mycoplasma hyopneumoniae, Pasteurella multocida, Bordetella bronchiseptica, Actinobacillus pleuropneumonia, Haemophilus parasuis, Streptococcus suis, Treponoma hyodysenteriae [9]. The animals were put in three SPFgrowing rooms with air filtration and low air pressure maintaining a level 3 of biosecurity.

\subsubsection{Experimental design}

Twenty-six six-week-old SPF piglets were divided into four groups as shown in Table I. Control piglets (groups 1 and 2) were assigned to the same room but in separate units.

One piglet in group 3 and one in group 4 were necropsied before the injections. Each of the other piglets in these two groups, received $800 \mu \mathrm{g}$ of tandem-cloned PCV2 genomic DNA by intramuscular injection in four sites (both sides of the neck and both hips). All animals in groups 2 and 4 were immunized with $2 \mathrm{mg}$ of keyhole limpet hemocyanin (Sigma-Aldrich, St. Louis, 
Table I. Constitution of the four groups and description of the experimental design.

\begin{tabular}{|c|c|c|c|}
\hline Group number & 2 & 3 & 4 \\
\hline Number of pigs & 5 & 8 & 8 \\
\hline \multicolumn{4}{|l|}{ Trial plan: } \\
\hline $\begin{array}{l}0 \text { day post-transfection } \\
\text { (dpt) }\end{array}$ & & $\begin{array}{l}\text { Infectious PCV2 DNA } \\
(800 \mu \mathrm{g} / \mathrm{pig}) \text { by IM }\end{array}$ & $\begin{array}{l}\text { Infectious PCV2 DNA } \\
(800 \mu \mathrm{g} / \mathrm{pig}) \text { by IM }\end{array}$ \\
\hline 4 and $7 \mathrm{dpt}$ & $\begin{array}{c}\text { KLH/ICFA by IM + } \\
\text { Thioglycollate broth by IP }\end{array}$ & & $\begin{array}{c}\text { KLH/ICFA by IM + } \\
\text { Thioglycollate broth by IP }\end{array}$ \\
\hline 11 and $19 \mathrm{dpt}$ & Thioglycollate broth by IP & & Thioglycollate broth by IP \\
\hline
\end{tabular}

The injections of DNA and keyhole limpet hemocyanin emulsified in incomplete Freund adjuvant (KLH/ ICFA) were administered by the intramuscular route (IM) and the injections of thioglycollate broth by the intraperitoneal route (IP).

MO, USA) emulsified in $4 \mathrm{~mL}$ of incomplete Freund adjuvant (Sigma-Aldrich) (KLH/ICFA) at 4 and 7 days post-transfection (dpt), and with $10 \mathrm{~mL}$ of $3 \%$ thioglycollate broth at 4, 7, 11 and $19 \mathrm{dpt}$. All the reagents injected to the piglets were sterilized. The KLH/ICFA was administered in four sites by intramuscular (IM) route, like the DNA, and the thioglycollate broth by the intraperitoneal (IP) route. One pig in each group was killed by intravenous booster of sodium pentobarbital at $12 \mathrm{dpt}$ and another at $21 \mathrm{dpt}$ in groups 3 and 4 . The experiment ended on day 32 post-transfection. Rectal temperatures and clinical assessments were recorded daily. The piglets were weighed and blood samples were taken weekly. At necropsy, tissue samples (tracheobronchial, inguinal, mesenteric, axillary and iliac lymph nodes; tonsil, spleen, ileum, lung, liver, thymus and heart) were collected for laboratory investigations and stored at $-80{ }^{\circ} \mathrm{C}$.

\subsection{Techniques of virology}

\subsubsection{Virus isolation}

The virus was extracted from tissue samples $(31 \% \mathrm{w} / \mathrm{v})$ with the help of a mechanical homogenizer (Bioblock Scientific, Illkirch, France) in ice cooled MEM medium (Gibco, Paisley, UK). The suspensions were centri- fuged at $2000 \mathrm{~g}$ for $15 \mathrm{~min}$ and the supernatants were stored at $-80^{\circ} \mathrm{C}$.

\subsubsection{Infectious virus titration}

PCV2 titration was assessed by an immunoperoxidase monolayer assay (IPMA) using a previously described protocol [12] with some modifications.

Supernatants of tissue homogenates were filtered through $0.22 \mu \mathrm{m}$ and diluted in MEM medium (Gibco) containing penicillin/streptomycin (P/S) (Gibco) and 5\% fetal calf serum (FCS) (PAN Biotech GmbH, Aidenbach, Germany). One-hundred microliters of each sample were spread over a PK15 mono-layer for $5 \mathrm{~h}$. The cells were then washed with sterile phosphate buffered saline (PBS) (Qbiogene, Illkirch, France) and the PCV2 replication was induced for $30 \mathrm{~min}$ at $37^{\circ} \mathrm{C}$ with $300 \mathrm{mMD}$-glucosamine (Sigma-Aldrich) in solution in Earle balanced salt solution (Sigma-Aldrich). After a wash with PBS (Qbiogene), the cells were incubated in MEM medium with FCS and $\mathrm{P} / \mathrm{S}$ for $36 \mathrm{~h}$ at $37{ }^{\circ} \mathrm{C}$ and then fixed with $80 \%$ cold acetone (Merck) for $10 \mathrm{~min}$ at $-20{ }^{\circ} \mathrm{C}$. The endogenous peroxidases were neutralized for $30 \mathrm{~min}$ with a solution of $\mathrm{H}_{2} \mathrm{O}_{2}$ /methanol (Merck) (1:99).

The fixed cells were then rinsed with PBS and successively incubated, with intermediate PBS-0.25\% Tween20 wash steps, 
for $1 \mathrm{~h}$ at $37{ }^{\circ} \mathrm{C}$ with PBS-3\% milk, $1 \mathrm{~h}$ at $37{ }^{\circ} \mathrm{C}$ with anti-PCV2 polyclonal serum diluted 1:300 in PBS-0.05\% Tween 20-5\% milk (PBS-TM) and finally $1 \mathrm{~h}$ at $37^{\circ} \mathrm{C}$ with a secondary peroxidase-conjugated rabbit anti-swine immunoglobulin (DAKO, Glostrup, Denmark) diluted 1:150 in PBS-TM. The colour was developed with 3-amino-9ethyl-carbazole (Serotec, Oxford, UK). The PCV2 titers were determined using the Kaerber method [20] and expressed in $\mathrm{TCID}_{50}$ per gram of tissue.

\subsection{Techniques of molecular biology}

\subsubsection{Inoculum production}

\subsubsection{Production of tandem-cloned PCV2 DNA}

The PCV2 genome (GenBank accession No. AF201311) was cloned in tandem in pBluescript KS+ (Stratagene, La Jolla, CA, USA) at the $\mathrm{SacI}$ site as described by Fenaux et al. [14]. DNA was produced at a concentration of $0.8 \mathrm{mg} / \mathrm{mL}$ without lipopolysaccharides $(0.046$ endotoxin unit $/ \mu \mathrm{g})$ by PlasmidFactory (Bielefeld, Germany). This solution was diluted to $0.2 \mathrm{mg} / \mathrm{mL}$ in endotoxin-free phosphate buffered saline (PBS) (Sigma-Aldrich) for our experiments.

\subsubsection{In vitro transfection}

Ninety percent-confluent PK15 cells were transfected with tandem-cloned PCV2 DNA using Lipofectamine ${ }^{\mathrm{TM}} 2000$ (Invitrogen, Carlsbad, CA, USA) according to the protocol supplied by the manufacturer. Twelve hours after transfection, the cells were fixed with $80 \%$ cold acetone for $10 \mathrm{~min}$ at $-20^{\circ} \mathrm{C}$ and PCV2 antigens were assessed by the immunoperoxidase monolayer assay method described previously.

\subsubsection{Quantification of PCV2 genomes by real-time $P C R$}

Virus DNA was extracted from the tissue homogenate supernatants with Qiagen
DNeasy tissue kit (Qiagen, Hilden, Germany) according to the manufacturer's instructions. The number of PCV2 genome copies was assessed by a TaqMan real-time PCR [7]. Briefly, the PCV2 specific primers 5,-GGGAGCAGGGCCAGAATT- 3 , (410427) and 5,-CGCTCTGTGCCCTTTGAATACT-3, (473-452) were designed into the PCV2 ORF2 region (GenBank accession no. AF201311) and amplified a 64bp fragment. The TaqMan probe 5,-ACCTTAACCTTTCTTATTCTG-3, (430-450) was labeled with the fluorescent reporter dye FAM (6-carboxyfluorescein) at the 5' end and with the non-fluorescent quencher (NFQ) associated with the minor groove binder at the 3 ' end.

A DNA solution of a plasmid carrying a single copy of the PCV2 genome was serial diluted and used to generate a standard curve of quantification. The reactions were performed on an ABI Prism 7000 thermocycler (Applied Biosystem, Foster City, CA, USA).

\subsection{Detection of PCV2 antigens}

The presence of PCV2 antigens in the samples was detected by immunochemistry. Fixed tissue sections were deparaffinized and rehydrated. The activities of endogenous peroxidases were neutralized for 7 min with hydrogen peroxide (DAKO). The slides were rinsed in PBS (Qbiogene) and incubated for $1 \mathrm{~h}$ at $37^{\circ} \mathrm{C}$ with $20 \mu \mathrm{L}$ of rabbit anti-PCV2-coat protein serum diluted 1:200.

The sections were then treated with goat biotin-labeled anti-rabbit-immunoglobulin antibody diluted $1: 200$ for $30 \mathrm{~min}$ at $37^{\circ} \mathrm{C}$, then with peroxidase-conjugated avidin (DAKO) for $30 \mathrm{~min}$ at room temperature and finally with diaminobenzidine for $10 \mathrm{~min}$ at room temperature, with PBS washes between each step. The slides were then counterstained with hematoxylin solution, washed and coverslipped. 


\subsection{Serology}

The PCV2 antibodies in the weekly-collected sera were detected and titrated using an ELISA test based on the recognition of a recombinant PCV2 capsid protein/GST fused protein and a GST protein [6]. Those samples with an OD ratio higher than 1.5 were considered positive for PCV2 antibodies.

\subsection{Gross pathology and histopathology}

At necropsy, the macroscopic lesions were assessed. A fragment of each sampled tissue was fixed in formalin (Sigma-Aldrich) for histological examination. The microscopic lesions were assessed on haemalumeosin-safranin stained tissue sections. The criteria required to diagnose PMWS were the commonly-established ones [38].

\subsection{Statistical analysis}

Relative daily weight gains, PCV2-antibody responses, genomic loads and infectious PCV2 titers were analyzed by the nonparametric U-test of Mann and Whitney using the SYSTAT 9 computer software package (SPSS Inc., Richmond, CA, USA).

\section{RESULTS}

\subsection{In vitro infectivity}

The detection of PCV2 antigens by IPMA in $10-15 \%$ of the transfected cells confirmed that our clone was infectious in vitro (data not shown).

\subsection{Clinical evaluation}

The piglets in the two control groups (nonimmunostimulated (1) and immunostimulated (2)) remained clinically normal throughout the trial as did the transfected piglets without immunostimulation (group 3). However, 2 of the 7 immunostimulated transfected piglets (group 4) showed pyrexia $\left(>40.5^{\circ} \mathrm{C}\right.$ ) for one day in the second week after transfection. And one pig (number 8003) in this group, presented high rectal temperatures from day 11 to day 19 posttransfection, associated with prolonged skin pallor. Enlargement of the inguinal lymph nodes (LN) was also detected after palpation of this animal from day 22 post-transfection. But no respiratory distress was noticed.

Compared to the non-immunostimulated control piglets (group 1), the daily weight gain (DWG) decreased in all the other groups in the second and third weeks posttransfection (wpt) (Fig. 1A). However growth retardation was only statistically significant $(p<0.05)$ in the third week for the immunostimulated transfected piglets (group 4). In this group, the relative DWG ranged from 0.64 to 0.75 in the third wpt for 3 piglets (Fig. 1B). In addition, piglet 8003 , which had suffered a long period of pyrexia, also exhibited severe wasting as early as the second wpt. Its relative DWG was 0.30 in the second wpt and 0.04 in the third. This piglet finally died at $29 \mathrm{dpt}$.

\subsection{Gross and microscopic lesions}

No lesions were observed in the control piglets throughout the experiment (Figs. 2A and 2B). The immunostimulated control animals (group 2) displayed minor hypertrophy only at the draining sites of the thioglycollate broth injection, namely the inguinal and iliac LN. However, no microlesions were noted in any of the tissues from this group except the presence of adjuvant lipid vacuoles in the $\mathrm{LN}$.

No gross lesions were apparent in the transfected animals, with (group 4) or without general immunostimulation (group 3), necropsied at 12 and $21 \mathrm{dpt}$. At $12 \mathrm{dpt}$, the piglets of both transfected groups displayed a diffuse interstitial pneumonia with pronounced thickening of the alveolar septa but without inflammation of the alveoli. The follicular structure tended to disappear in the LN. At $21 \mathrm{dpt}$, only moderate interstitial pneumonia was still detectable in the piglets of those groups. 
A

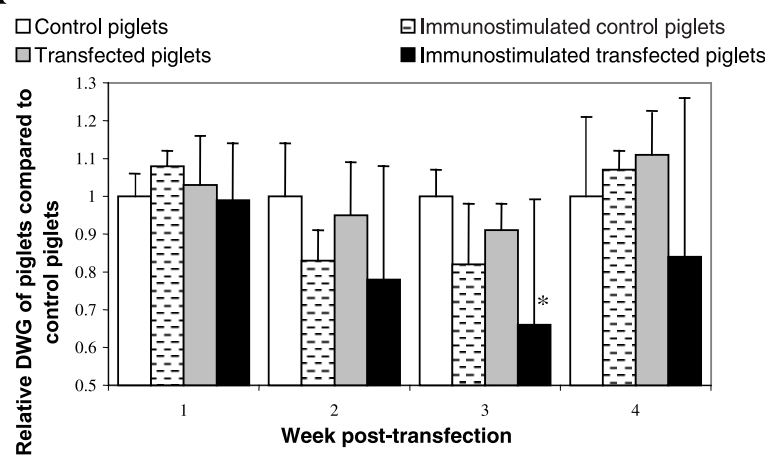

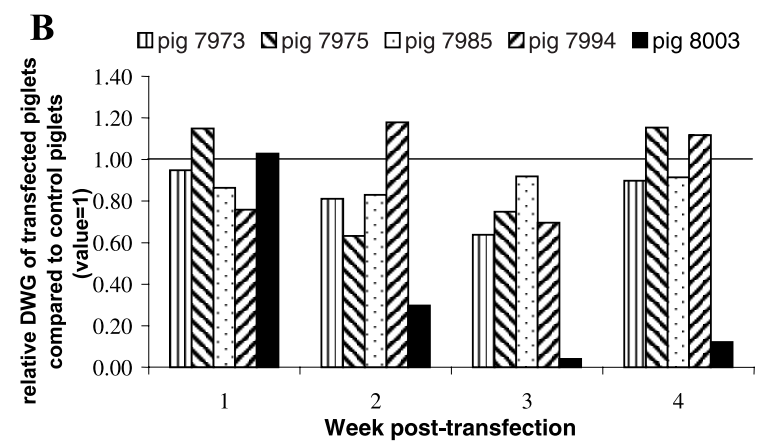

Figure 1. (A) Impact of the transfection on the relative daily weight gain (rDWG) assessed for each group by comparison of piglet daily weight gains with those of control piglets. The asterisk represents a significant difference $(p<0.05)$ with the control group. (B) Individual relative daily weight gains of the 5 immunostimulated transfected piglets that were necropsied after the third week post-injection.
At the end of the trial, the enlargement of at least one LN (the tracheobronchial and/or the axillary LN) was observed in 2 of the 5 transfected piglets (group 3) and in all 5 immunostimulated transfected piglets (group 4). Only lung lesions were observed in the transfected piglets (group 3) and were characterized as mild-to-moderate interstitial pneumonia. At $32 \mathrm{dpt}$, in immunostimulated transfected animals (group 4) apart from piglet 8003 , examination of the microlesions revealed necrosis of a few hepatocytes as well as more pronounced interstitial pneumonia around the bronchioles. PCV2 antigens were revealed within the lungs by immunochemistry. According to the criteria required to diagnose PMWS, 1 of these 4 immunostimulated transfected piglets showed a mild form of PMWS meaning moderate microlesions in lungs and the presence of PCV2 within the lesions in tissue. The other piglets presented a moderate form with pyrexia and/or decrease of relative DWG, moderate microlesions and presence of PCV2 antigens in the lungs. As already mentioned, the last piglet of this group (8003) had well-defined clinical signs and died at $29 \mathrm{dpt}$. Its thymus was atrophied and lymphadenopathy of the tracheobronchial, axillary, inguinal and iliac LN was detected. Gastric ulceration was also observed. The kidneys revealed no gross lesions and thus, were not collected for histopathological examination. Severe lymphocyte depletion was noted in all the LN samples and in the Peyer patches, associated with loss of follicles and histiocytic infiltration (Fig. 3A). PCV2 antigens were detected in the cell cytoplasm and cell nuclei within these tissues by immunohistochemistry (Fig. 3B). 

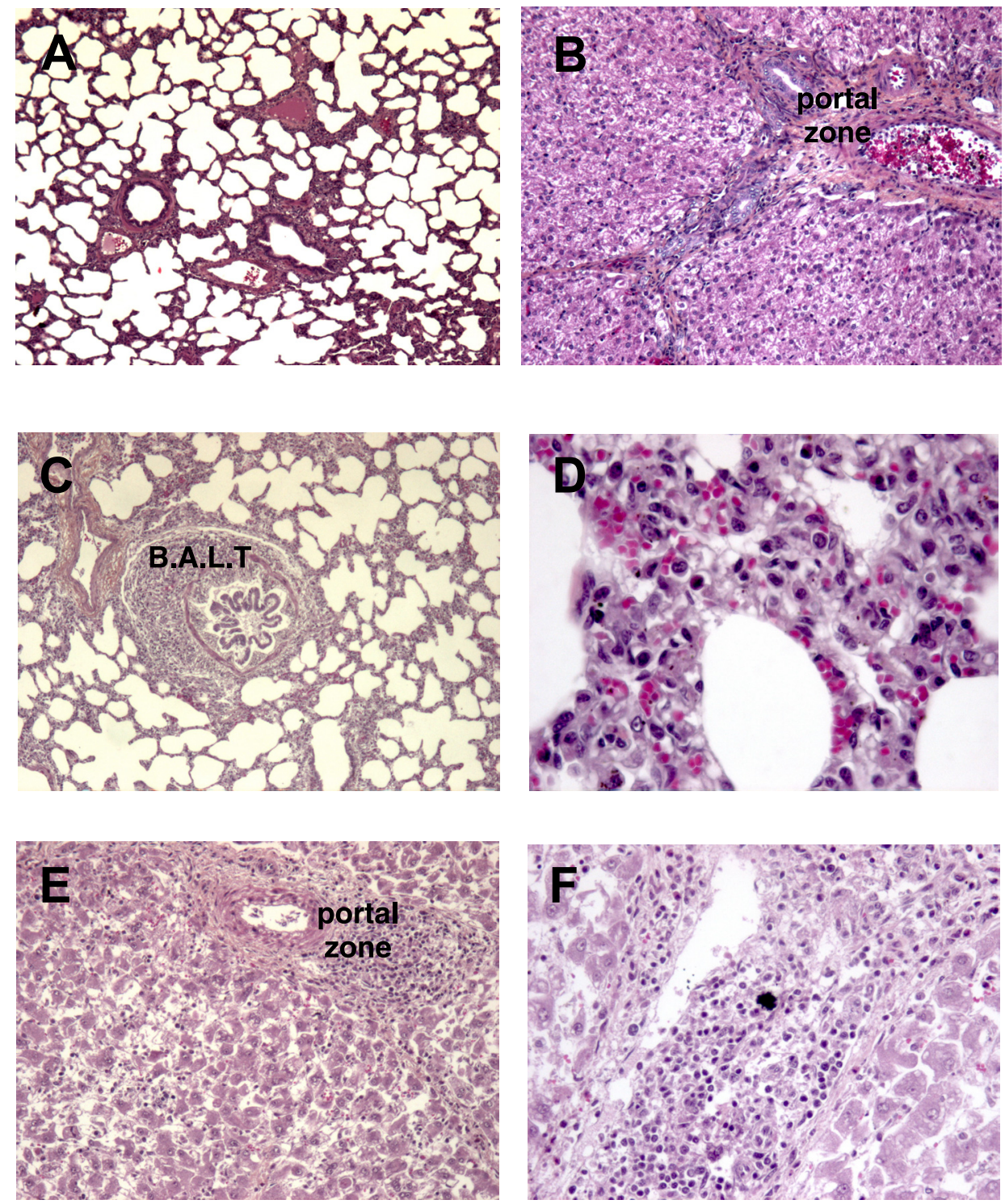

Figure 2. Microscopic sections of organs from a control piglet (A, B) and from the immunostimulated transfected pig (number 8003) which died at $29 \mathrm{dpt}$ of PMWS (C, D, E, F). Haemalumeosin-safranin stain. (A) Normal structure of lungs $(\times 50)$. (B) Liver with typical portal-zone and well-defined lobules $(\times 100)$. (C) Lung with interstitial pneumonia and B.A.L.T. hyperplasia $(\times 50)$. (D) Inflammation of the alveolar septa $(\times 200)$. (E) Liver showing inflammatory infiltration of the portal zone and disorganization of the hepatocyte lobular structure $(\times 100)$. $(\mathbf{F})$ Magnification of the inflammatory portal zone $(\times 200)$ (see www.edpsciences.org/vetres for a colour version of this figure). 

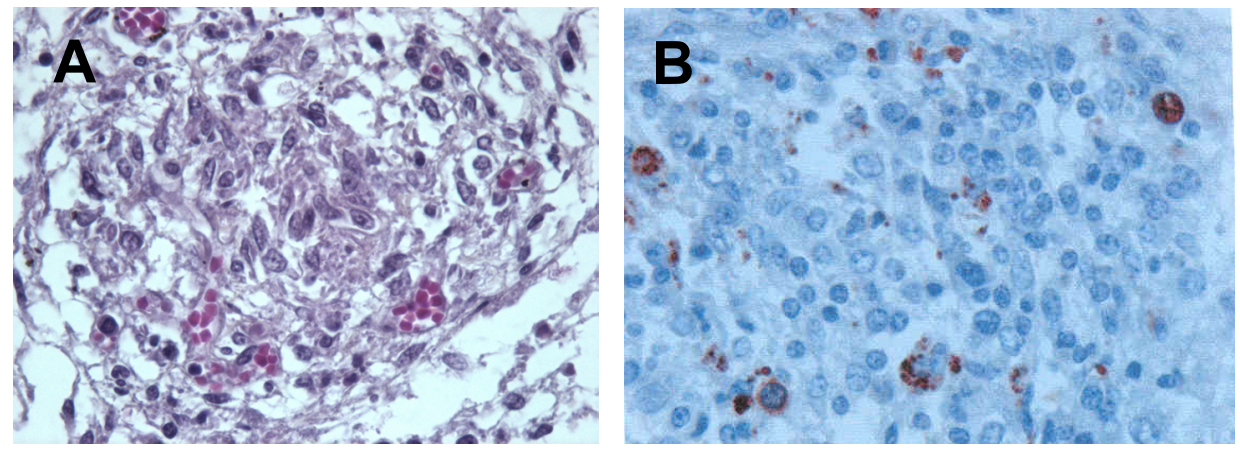

Figure 3. (A) Inguinal lymph node histopathology of the immunostimulated transfected pig which died of PMWS at $29 \mathrm{dpt}$. Severe lymphocyte depletion and absence of follicles. Hematoxylin and eosin stain $(\times 400)$. (B) Immunohistochemical staining of the inguinal lymph node previously shown in Figure 3A. Presence of PCV-2 antigens in the cytoplasm and nucleus $(\times 400)$ (see www.edpsciences.org/vetres for a colour version of this figure).

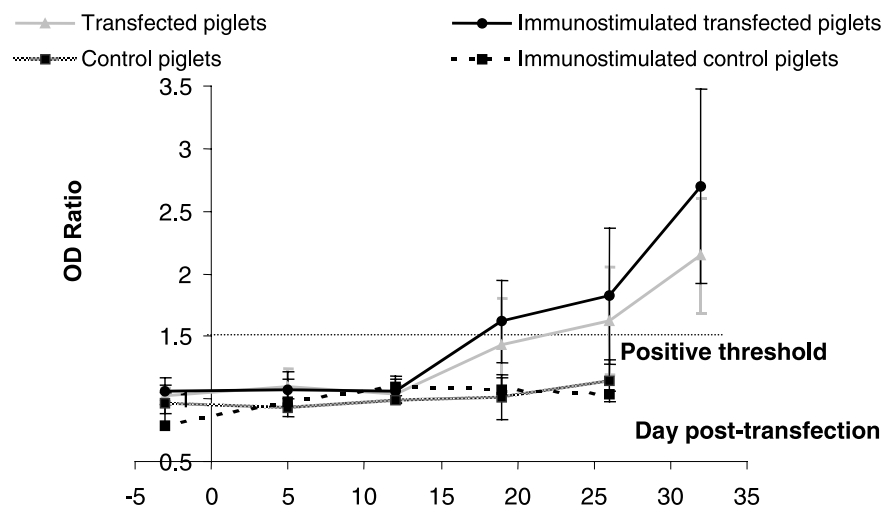

Figure 4. PCV2-antibody responses monitored by PCV2-ORF2 protein ELISA. The positive cutoff was set at an OD ratio of 1.5 obtained between ORF2-GST and GST values. 100-fold diluted sera were assessed against PCV2-ORF2 recombinant protein.

The alveolar septa infiltration with mononuclear cells suggested the presence of multifocal lymphohistiocytic interstitial pneumonia (Fig. 2C). Hyperplasia of the Bronchusassociated lymphoid tissue (B.A.L.T.) was also observed. The portal zones of the liver presented lymphocytic inflammation. The liver plates were disorganized and necrosis had occurred in many hepatocytes (Fig. 2D). According to the lesions and the clinical signs, this piglet suffered from severe PMWS.

\subsection{PCV2-ORF2 antibody response}

The pigs in the two control groups remained seronegative for PCV2 antibodies throughout the study (Fig. 4). No PCV2-antibodies were detected in the sera of the transfected pigs (group 3) and the immunostimulated transfected pigs (group 4) before transfection. All the immunostimulated transfected piglets (group 4) seroconverted between 19 and 26 dpt except piglet 8003 which 


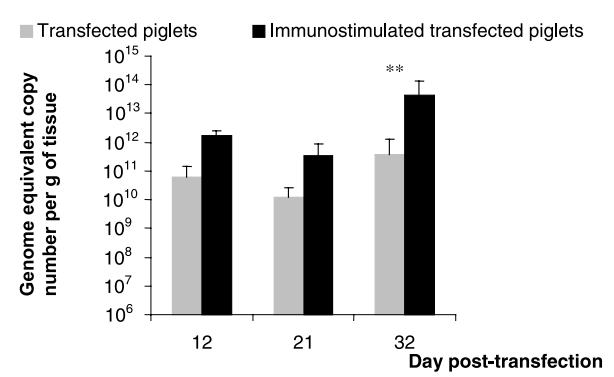

Figure 5. PCV2 genome copy numbers in lymphoid organs (tracheobronchial, axillary, mesenteric, inguinal, iliac nodes, tonsil and spleen) measured by real-time quantitative PCR. The values are expressed in genome equivalent copy number (GECN) per gram of tissue and are the mean of the GECN obtained in the lymphoid organs of all the transfected piglets with or without immunostimulation at several times. Asterisks indicate a significant difference $(p<$ 0.005 for $* *$ ) when groups 3 and 4 were compared with each other.

remained seronegative for $29 \mathrm{dpt}$. The PCV2-antibody response increased from the second week onwards, the mean of the OD ratios reaching a maximum of 2.7 on day $32 \mathrm{pt}$ for the immunostimulated transfected pigs (group 4). In the absence of immunostimulation, the complete seroconversion of transfected animals (group 3) was slightly delayed and occurred between $19 \mathrm{dpt}$ and the end of the trial, when the mean OD ratio was 2.15 .

\subsection{PCV2 genome load in tissues}

No PCV2 genomic loads were detected in any tissues from the control piglets (groups 1 and 2) or in those of the transfected piglets (groups 3 and 4) at $-1 \mathrm{dpt}$. After transfection (groups 3 and 4), the lymph nodes (tracheobronchial, inguinal, mesenteric, axillary and iliac LN) and some lymphoid tissues (tonsil, spleen and ileum) exhibited the highest PCV2-genome equivalent copy number (GECN) per gram of tissue compared to the other tissues (thymus, lung, liver and heart). Thus, the PCV2 genomic load was calculated in these organs (Fig. 5). After the DNA injection, the PCV2 DNA copy number increased in transfected animals without (group 3) or with immunostimulation (group 4). The viral load of the immunostimulated transfected pig $(1.64 \times$ $10^{12}$ GECN per gram of tissue) was higher at $12 \mathrm{dpt}$ than that of the non-immunostimulated pig $\left(6.1 \times 10^{10}\right.$ GECN per gram of tissue). On day 32 post-transfection, the viral DNA load was more than 100 -fold higher $(p \leq 0.005)$ in the lymphoid tissues of the immunostimulated transfected piglets $\left(4.2 \times 10^{13}\right.$ GECN per gram of tissue) than in those of the transfected pigs (group 3) $\left(3.76 \times 10^{11}\right.$ GECN per gram of tissue). The maximum PCV2 genomic load was found in the lymphoid tissues of piglet 8003, which presented severe lesions, and attained an average of $2.08 \times 10^{14}$ GECN per gram of tissue. The tracheobronchial, axillary and iliac LN showed the highest genomic loads ranging between 2.54 and $3.4 \times 10^{14}$ GECN per gram of tissue. In all the tissues of the piglet 8003 , the genomic load was higher than $2 \times 10^{13}$ GECN per gram of tissue. Interestingly, immunostimulation affected the PCV2 viral load in the lymphoid tissues of the transfected animals.

\subsection{Evolution of the infectious viral titers}

No infectious viral particles were detected in the organs (tracheobronchial, axillary and inguinal LN) of the control pigs (groups 1 and 2). The increase observed at $12 \mathrm{dpt}$ in the transfected animals immunostimulated (group 4) or not (group 3), was followed by a decrease at $21 \mathrm{dpt}$ (Fig. 6). Finally, the titers reached their highest level in the LN (tracheobronchial, axillary and inguinal LN) of non-immunostimulated and immunostimulated piglets with respective means of $10^{4.2}$ and $10^{6.7}$ TCID $_{50}$ per gram of tissue. The maximum titer was obtained in the LN of pig 8003 with $10^{7.3}$ TCID $_{50}$ per gram of tissue. At $12 \mathrm{dpt}$, infectious viral particles were more numerous in the tracheobronchial 


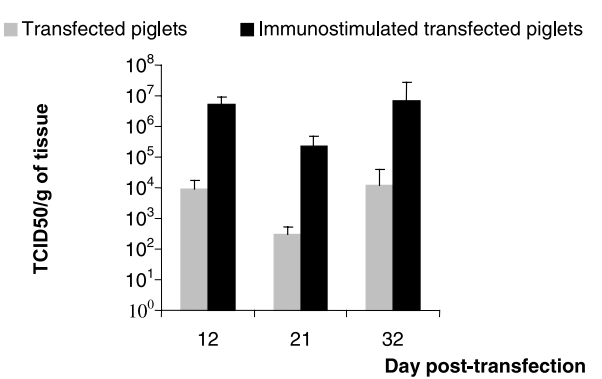

Figure 6. Evolution of infectious-PCV2 titers in tracheobronchial, axillary and inguinal lymph nodes from transfected piglets immunostimulated (in black) or not (in grey). The means are expressed in $\mathrm{TCID}_{50}$ per gram of tissue.

and axillary LN adjacent to the DNA injection sites than in the inguinal LN (data not shown).

\section{DISCUSSION}

The aim of this study was to evaluate the impact of a general immunostimulation on the pathogenicity of an infectious PCV2 molecular DNA clone in six-week-old SPF piglets.

The piglets transfected with tandemcloned PCV2 DNA by intramuscular route (group 3) did not present any clinical signs (such as pyrexia and wasting) but rather the mild pathological lesions characteristic of PMWS as previously described [32]. However, the seroconversion profile matched that observed in SPF pigs after infection with a crude viral isolate [6] thus indicating a successful production of viral antigens and the consequent response of the immune system. A high number of GECN per gram of tissue $\left(3.7 \times 10^{11}\right.$ GECN per gram) was found in the lymphoid organs (tracheobronchial, inguinal, mesenteric, axillary and iliac LN, tonsil, spleen and ileum) as well as many infectious particles $\left(10^{4.2}\right.$ TCID $_{50}$ per gram) at $32 \mathrm{dpt}$. Significant titers of infectious virus were first detected in the tracheobronchial and axillary LN. Hence, the virus replicated efficiently in animals transfected with the PCV2 genomic clone and spread subsequently throughout the organism. A threshold of $10^{11}$ GECN per gram of tissue in the lymphoid organs has been suggested for the diagnosis of PMWS [7]. The genomic loads in the lymphoid tissues of the non-immunostimulated transfected piglets were below or equal to this level which would explain the absence of clinical signs and severe microlesions.

In contrast, mild-to-severe forms of PMWS were observed in piglets that received a systemic immunostimulation in addition to the tandem-cloned PCV2 DNA (group 4) and for the first time, a severe form of PMWS was reproduced in one of those pigs. Out of the five piglets remaining at the end of the trial in group 4, one displayed a mild form of PMWS while three exhibited a moderate form. These pigs seroconverted earlier than the group 3 animals. At the end of the experiment, the genome loads in their lymphoid tissues were higher than those of the transfected-only piglets (group 3 ). The infectious titers in the tracheobronchial, axillary and inguinal LN were similar to those of group 3. Thus, immunostimulation, consisting of KLH emulsified in ICFA and thioglycollate broth enhanced viral replication in most piglets. The PCV2 genomic loads did not exceed the diagnosis threshold of $10^{11}$ GECN per gram of tissue as suggested by Blanchard et al. [7]. This may explain why only mild-to moderate forms of PMWS were developed by these piglets. The noticeable exception in this group 4 was piglet 8003 which showed severe PMWS as shown by (i) growth retardation from the second wpt onwards, (ii) prolonged hyperthermia for nine days and (iii) typical macro- and micro-lesions and (iv) the highest genomic load among all the transfected animals [37]. High levels of PCV2 antigens were detected in the lymphoid organs in which the genomic load and viral titer reached $2.08 \times 10^{14} \mathrm{GECN}$ and $10^{7.3}$ TCID $_{50}$ per gram of tissue respectively. The suggested threshold of $10^{11}$ GECN per gram of tissue was exceeded and clinical PMWS was well-characterized in this 
piglet. The tests performed at the beginning of the trial to control the presence of several pathogens in the SPF piglets, the use of sterile reagents and pure DNA solution, and the strict control conditions in our facilities, allowed us to assume that the piglet 8003 was only infected by PCV2. However, this piglet did not seroconvert during the experiment. An ELISA test performed on the serum of this piglet revealed that it possessed a normal level of immunoglobulins at the beginning of the trial (data not shown). Therefore, immunosuppression may have occurred in the course of the experiment possibly due to a rapid decrease in B cells which could be confirmed by the massive loss of lymphoid follicles (B-cell dependent areas) in the lymphoid organs. It had already been demonstrated that depletion of the follicular areas was correlated with the decrease in the number of circulating B cells [36]. The neutralization of viral particles by PCV2-specific antibodies could also reduce the level of PCV2 antibodies. Indeed, it has already been reported that piglets showing severe PMWS and high levels of genomic loads have presented low or undetectable PCV2 antibody levels [25]. The immunostimulation with KLH/ICFA and thioglycollate broth improves PCV2 replication but this impact can be counterbalanced by the immune response of individual piglets which can reduce the number of infectious particles produced.

The KLH associated with incomplete Freund adjuvant stimulates the humoral and cell-mediated immune responses whereas the thioglycollate medium activates the peritoneal macrophages [23]. The reagents used in our study mainly triggered the $\mathrm{TH}_{2}$ immune response. This specific immune response may have a preponderant role in the expression of this disease. Other authors have reported, however, that immunostimulations also enhancing the $\mathrm{TH}_{2}$ immune response do not have a critical effect on intensifying PMWS [25, 31]. Resendes et al. failed to reproduce PMWS in conventional pigs even with immunostimulation, although they noted that this stimulation produced a slight increase in viral replication [31]. Ladekjaer-Mikkelsen et al. succeeded in reproducing PMWS in SPF piglets, whether immunostimulated or not with KLH emulsified in ICFA. Although this immunostimulation was not essential to the development of PMWS, it apparently influenced the immune response to the virus [25] and its impact could differ according to the animals' sanitary status and the PCV2 inoculum. Thus despite the conflicting results obtained in previous studies, it is apparent from our work that the immune stimulation is an important key in the manifestation of PMWS.

In conclusion, we are reporting for the first time the reproduction of clinical PMWS in an SPF immunostimulated piglet infected with a pure inoculum of tandem-cloned PCV2 DNA. The severity of the disease is enhanced by other factors such as the immunostimulation used in this work which had an impact on the viral replication. This study confirmed that the intramuscular route is an efficient way for in vivo transfection of an infectious PCV2 DNA clone. However, since the respiratory route has been proposed to be the principal route of transmission of this virus, this other way should be tested for transfection.

\section{ACKNOWLEDGMENTS}

The authors are grateful to Bernard Beaurepaire, Gérard Bennevent, Jean-Claude Rault, André Kéranflec' $h$ and Bruno Jan for the experimental work on the animals in the AFSSA facilities. We also thank Nadia Amenna for the histopathology and Isabelle Méderlé-Mangeot for her helpful discussions.

\section{REFERENCES}

[1] Albina E., Truong C., Hutet E., Blanchard P., Cariolet R., L'Hospitalier R., Mahe D., Allee C., Morvan H., Amenna N., Le Dimna M., Madec F., Jestin A., An experimental model for post-weaning multisystemic wasting syndrome (PMWS) in growing piglets, J. Comp. Pathol. 125 (2001) 292-303. 
[2] Allan G.M., McNeilly F., Kennedy S., Daft B., Clarke E.G., Ellis J.A., Haines D.M., Meehan B.M., Adair B.M., Isolation of porcine circovirus-like viruses from pigs with a wasting disease in the USA and Europe, J. Vet. Diagn. Invest. 10 (1998) 3-10.

[3] Allan G.M., Kennedy S., McNeilly F., Foster J.C., Ellis J.A., Krakowka S.J., Meehan B.M., Adair B.M., Experimental reproduction of severe wasting disease by co-infection of pigs with porcine circovirus and porcine parvovirus, J. Comp. Pathol. 121 (1999) 1-11.

[4] Allan G.M., McNeilly F., Kennedy S., Meehan B., Ellis J., Krakowka S., Immunostimulation, PCV-2 and PMWS, Vet. Rec. 147 (2000) 170-171.

[5] Balasch M., Segales J., Rosell C., Domingo M., Mankertz A., Urniza A., Plana-Duran J., Experimental inoculation of conventional pigs with tissue homogenates from pigs with post-weaning multisystemic wasting syndrome, J. Comp. Pathol. 121 (1999) 139-148.

[6] Blanchard P., Mahe D., Cariolet R., Truong C. Le Dimna M., Arnauld C., Rose N., Eveno E., Albina E., Madec F., Jestin A., An ORF2 protein-based ELISA for porcine circovirus type 2 antibodies in post-weaning multisystemic wasting syndrome, Vet. Microbiol. 94 (2003) 183-194.

[7] Blanchard P., Loizel C., Baudouard M.A., Nignol A.C., Grasland B., Dory D., Morvan H., Cariolet R., Jestin A., Quantification du génome du circovirus porcin de type 2 (PCV2) par PCR en temps réel et corrélation avec la maladie d'amaigrissement du porcelet (MAP), Journ. Rech. Porcine France 36 (2004) 327 332.

[8] Bolin S.R., Stoffregen W.C., Nayar G.P., Hamel A.L., Postweaning multisystemic wasting syndrome induced after experimental inoculation of cesarean-derived, colostrumdeprived piglets with type 2 porcine circovirus, J. Vet. Diagn. Invest. 13 (2001) 185-194.

[9] Cariolet R., Marie P., Moreau G., Robert H., Summary of the different methods for producing, maintaining and benefiting from piglets of high health status, J. Rech. Porcine France 26 (1994) 1-12.

[10] Clark E., Post-weaning multisystemic wasting syndrome, American Association of Swine Practitioners, 1997, pp. 499-501.

[11] Daft B., Nordhausen R.W., Latimer K.S., Niagro F.D., Interstitial pneumonia and lymphadenopathy associated with circoviral infection in a six-week-old pig, Proc. Am. Assoc. Vet. Lab. Diagn. 39 (1996) 32.

[12] Ellis J., Hassard L., Clark E., Harding J., Allan G., Willson P., Strokappe J., Martin K., McNeilly F., Meehan B., Todd D., Haines D., Isolation of circovirus from lesions of pigs with postweaning multisystemic wasting syndrome, Can. Vet. J. 39 (1998) 44-51.

[13] Ellis J., Krakowka S., Lairmore M., Haines D., Bratanich A., Clark E., Allan G., Konoby C., Hassard L., Meehan B., Martin K., Harding J., Kennedy S., McNeilly F., Reproduction of lesions of postweaning multisystemic wasting syndrome in gnotobiotic piglets, J. Vet. Diagn. Invest. 11 (1999) 3-14.

[14] Fenaux M., Halbur P.G., Haqshenas G., Royer R., Thomas P., Nawagitgul P., Gill M., Toth T.E., Meng X.J., Cloned genomic DNA of type 2 porcine circovirus is infectious when injected directly into the liver and lymph nodes of pigs: characterization of clinical disease, virus distribution, and pathologic lesions, J. Virol. 76 (2002) 541-551.

[15] Fenaux M., Opriessnig T., Halbur P.G., Meng X.J., Immunogenicity and pathogenicity of chimeric infectious DNA clones of pathogenic porcine circovirus type 2 (PCV2) and nonpathogenic PCV1 in weanling pigs, J. Virol. 77 (2003) 11232-11243.

[16] Hardge T., Gausman H., Hasberg W., Lange S., The economic impact of PMWS in the nursery, Intern. Pig Topics 18 (2003) 11-12.

[17] Harding J., Post-weaning multisystemic wasting syndrome (PMWS): preliminary epidemiology and clinical presentation, American Association of Swine Practitioners, 1997, p. 503.

[18] Harding J., Clark E., Recognizing and diagnosing postweaning multisystemic wasting syndrome (PMWS), Swine Health Prod. 5 (1997) 201-203.

[19] Harms P.A., Sorden S.D., Halbur P.G., Bolin S.R., Lager K.M., Morozov I., Paul P.S., Experimental reproduction of severe disease in $C D / C D$ pigs concurrently infected with type 2 porcine circovirus and porcine reproductive and respiratory syndrome virus, Vet. Pathol. 38 (2001) 528-539.

[20] Kaerber G., Beitrag zur kollectiven behandlung pharmakologischer. Reihenversuche, Arch Pharmakol. Exp. Pathol. 162 (1931) 480-483.

[21] Kennedy S., Moffett D., McNeilly F., Meehan B., Ellis J., Krakowka S., Allan G.M., Reproduction of lesions of postweaning multisystemic wasting syndrome by infection of 
conventional pigs with porcine circovirus type 2 alone or in combination with porcine parvovirus, J. Comp. Pathol. 122 (2000) 9-24.

[22] Krakowka S., Ellis J.A., Meehan B., Kennedy S., McNeilly F., Allan G., Viral wasting syndrome of swine: experimental reproduction of postweaning multisystemic wasting syndrome in gnotobiotic swine by coinfection with porcine circovirus 2 and porcine parvovirus, Vet. Pathol. 37 (2000) 254-263.

[23] Krakowka S., Ellis J.A., McNeilly F., Ringler S., Rings D.M., Allan G., Activation of the immune system is the pivotal event in the production of wasting disease in pigs infected with porcine circovirus-2 (PCV-2), Vet. Pathol. 38 (2001) 31-42.

[24] Kyriakis S.C., Saoulidis K., Lekkas S., Miliotis C.C., Papoutsis P.A., Kennedy S., The effects of immuno-modulation on the clinical and pathological expression of postweaning multisystemic wasting syndrome, J. Comp. Pathol. 126 (2002) 38-46.

[25] Ladekjaer-Mikkelsen A.S., Nielsen J., Stadejek T., Storgaard T., Krakowka S., Ellis J., McNeilly F., Allan G., Botner A., Reproduction of postweaning multisystemic wasting syndrome (PMWS) in immunostimulated and non-immunostimulated 3-week-old piglets experimentally infected with porcine circovirus type 2 (PCV2), Vet. Microbiol. 89 (2002) 97-114.

[26] Madec F., Eveno E., Morvan P., Hamon L., Blanchard P., Cariolet R., Amenna N., Morvan H., Truong C., Mahe D., Albina E., Jestin A., Post-weaning multisystemic wasting syndrome (PMWS) in pigs in France: clinical observations from follow-up studies on affected farms, Livest. Prod. Sci. 63 (2000) 223.

[27] Magar R., Larochelle R., Thibault S., Lamontagne L., Experimental transmission of porcine circovirus type 2 (PCV2) in weaned pigs: a sequential study, J. Comp. Pathol. 123 (2000) 258-269.

[28] Meehan B.M., McNeilly F., Todd D., Kennedy S., Jewhurst V.A., Ellis J.A., Hassard L.E., Clark E.G., Haines D.M., Allan G.M., Characterization of novel circovirus DNAs associated with wasting syndromes in pigs, J. Gen. Virol. 79 ( Pt 9) (1998) 2171-2179.

[29] Onuki A., Abe K., Togashi K., Kawashima K., Taneichi A., Tsunemitsu H., Detection of porcine circovirus from lesions of a pig with wasting disease in Japan, J. Vet. Med. Sci. 61 (1999) 1119-1123.
[30] Opriessnig T., Yu S., Gallup J.M., Evans R.B., Fenaux M., Pallares F., Thacker E.L., Brockus C.W., Ackermann M.R., Thomas P., Meng X.J., Halbur P.G., Effect of vaccination with selective bacterins on conventional pigs infected with type 2 porcine circovirus, Vet. Pathol. 40 (2003) 521-529.

[31] Resendes A., Segales J., Balasch M., Calsamiglia M., Sibila M., Ellerbrok H., Mateu E., PlanaDuran J., Mankertz A., Domingo M., Lack of an effect of a commercial vaccine adjuvant on the development of postweaning multisystemic wasting syndrome (PMWS) in porcine circovirus type 2 (PCV2) experimentally infected conventional pigs, Vet. Res. 35 (2004) 83-90.

[32] Roca M., Balasch M., Segales J., Calsamiglia M., Viaplana E., Urniza A., Hattermann K., Mankertz A., Plana-Duran J., Domingo M., In vitro and in vivo characterization of an infectious clone of a European strain of porcine circovirus type 2, J. Gen. Virol. 85 (2004) 12591266.

[33] Rosell C., Segales J., Plana-Duran J., Balasch M., Rodriguez-Arrioja G.M., Kennedy S., Allan G.M., McNeilly F., Latimer K.S., Domingo M., Pathological, immunohistochemical, and in-situ hybridization studies of natural cases of postweaning multisystemic wasting syndrome (PMWS) in pigs, J. Comp. Pathol. 120 (1999) 59-78.

[34] Segales J., Domingo M., Postweaning multisystemic wasting syndrome (PMWS) in pigs. A review, Vet. Q. 24 (2002) 109-124.

[35] Segales J., Sitjar M., Domingo M., Dee S., Del Pozo M., Noval R., Sacristan C., De las Heras A., Ferro A., Latimer K.S., First report of postweaning multisystemic wasting syndrome in pigs in Spain, Vet. Rec. 141 (1997) 600-601.

[36] Segales J., Alonso F., Rosell C., Pastor J., Chianini F., Campos E., Lopez-Fuertes L., Quintana J., Rodriguez-Arrioja G., Calsamiglia M., Pujols J., Dominguez J., Domingo M., Changes in peripheral blood leukocyte populations in pigs with natural postweaning multisystemic wasting syndrome (PMWS), Vet. Immunol. Immunopathol. 81 (2001) 37-44.

[37] Segales J., Domingo M., Chianini F., Majo N., Dominguez J., Darwich L., Mateu E., Immunosuppression in postweaning multisystemic wasting syndrome affected pigs, Vet. Microbiol. 98 (2004) 151-158.

[38] Sorden S., Update on porcine circovirus and post-weaning multisystemic wasting syndrome (PMWS), Swine Health Prod. 8 (2000) 133136. 